\title{
Information System for Trust Food Supply Management
}

\author{
D. Davcev, L. Kocarev \\ K. Mitreski
}

\author{
M. Florea
}

\author{
A. Carbone
}

V. Stankovski

\begin{abstract}
This paper is inspired by the project proposal ID 773937-1 submitted for the Horizon 2020 topic SFS-34-2017. It aims to provid an information system for cooperative trusted food supply chain management and in this way to unlock great potential for competitiveness and sustainability. A new holistic approach to the design of trusted applications and services will deliver economic, social and environmental benefits. Blockchain technologies will enhance the transparency, information flow and management capacity allowing better interactions of farmers with other part of supply chain, especially the consumer. In this research we propose new food-on-demand business model, based on new Quality of Experience (QoE) food metrics, bridging the gap between subjective experience and objective matrics based on quality standards. Special attention will be paid to the concept of social innovation by introducing new tools for trusted analysis of customer behaviour and the ways of measuring the customer satisfaction throughout the value chain. As a case study, we instaled a group of sensors based on LoraWAN technology on the grape farm near the City of Skopje (near to the river Vardar). In addition, we provided a survey with 30 University' students about their trust in food supply chain (trust study).
\end{abstract}

Keywords-Trusted cooperative supply chain, food ondemand business model, customer behaviour, Quality of Experience (QoE),

D.Davcev, L. Kocarev, K. Mitreski

Macedonian Academy of Science and Art, Center for Computer Science \& Information Technologies

Skopje, R. Macedonia M. Florea Siveco

Bucharest, Romania

A. Carbone

Politecnico di Torino

Torino, Italy

V. Stankovski

University of Ljubljana (UL)

Ljubljana, Slovenia,

\section{INTRODUCTION}

Trust plays significant role in the food supply chains sector and may significantly contribute to greater degree of vertical and horizontal cooperation. Important elements contributing to trust among the stakeholders include assurance of the products' quality and the reliable products delivery, which leads to winwin situations across the socio-economic, organizational, regulatory and environmental domains.

Recent developments in areas such as Open Data, Cooperative Smart Infrastructures, Social Networks, Cloud (Mobile) Computing, the Internet of Things (IoT), Big Data technologies, RFID and NFC tags, Blockchain and various innovative applications on top of them may all be used as instruments for building trust among the stakeholders.

The key goal of the this research is to propose an innovative Information System for Trust Food SupplyManagement based on the emerging ICT technologies as well to foster high quality of products and thus contributes to trust building measures beyond what is possible to be achieved under current standard-based certification schemes.

The research focuses at few essential steps of the food chain, and addresses the emergent needs of core stakeholders, encompassing farm production, packaging, transport, and warehousing (food storage) companies. The study focuses on one typical food product - grapes (as a case study), the quality of which is specifically difficult to observe - from farm production, through the packaging and transport, up to its adequate storage by various companies in the supply chain. The results of the study are applicable for any food product, so it will provide quite generic solutions.

An overview of the main objectives of this research connected to the above processes is given as follows:

-To provide food customization by analysis of consumer behavior and usage of direct and trusted feedback from consumers to producers about the content, the quality, the taste, and other characteristic of the food products, which are then analyzed from producers to create more customized offers.

- By using the circular economy model [7] and by following the shelf life deadline of the food products on the basis of trusted information from the information system to provide the trusted food waste reduction. 
- To create new cooperative food on- demand business model giving the possibility to consumers to order and monitor the customized food products specifying the source, quality, quantity, speed, time, place of delivery, etc.

- To enable advanced food traceability by applying the Blockchain technology [8].

- To introduce new Quality of Experience (QoE) [6] food metrics and bridge the gap between the subjective consumer perception and objective quality standards and models in order to provide trusted estimation of the level of consumer's satisfaction. QoE is applied to the whole cooperative chain.

The paper is organized as follows. Section II presents the concept and methodology used to provide the TRUST. Section III gives the modeling and implementation issues, while in Section IV we give some details about our preliminary case study. In Section V we give the trust study while Section VI concludes the paper.

\section{Architecture of Open Trust Food SUPPLY MANAGEMENT INFORMATION SYSTEM}

\section{A. The concept}

Fig. 1 presents the framework of the food supply chain under consideration in this project. In our decentralized approach, we propose micro data centers located at the edge of the network instead of large-centralized Cloud Computing infrastructures. These micro data centers are closer to a user (geographically and in access latency) compared to the centralized cloud data center. The aim of utilizing such edge resources is to off load computation that would have "traditionally" been carried out at the cloud data center to a resource that is closer to a user or edge devices.

Consequentely, the consumers may order and monitor via the decentralized information system the customized food products specifying the source, quality, quantity, speed, time and place of delivery and other specific requirements. Innovative trusted tools for analysis of customer behavior as well as direct feedback from the customers could be analyzed. By using the QoE food metrics, the producers will have to take into account not only the quality measures according to regulations and standards, but also the estimation of the level of consumer's satisfaction.
In the second step, we assume an efficient and trusted packaging

Next, we also assume data from the food transport available to the consumer via the information system. It is very important for the consumer to know how his products are transported including reliability, safety and security aspects.

Food waste reduction will be possible via the creation of specific process for following the shelf life deadline of the food products on the basis of data from the information system.

Finally, food traceability along the whole product lifecycle including quality, quantity, adulteration and authentication is a key consumer's tool to control the whole food supply chain activities.

\section{B. Methodology}

Real-world smart environments will be used for the purpose of this research. This will include a case study for the grape farm near the City of Skopje (see Section IV). Small farms need sophisticated sensing activities at soil and plant level. Sensors will be configured to collect data for various applications. Spatially-enabled mobile sensing technologies will provide detailed analysis of field conditions such as the humidity in different soil layers, the amount of nutrients in the soil, temperature, luminosity, solar visible radiation, rainfall, wind direction and speed, atmospheric pressure, leaf wetness and fruit or trunk diameter measurement (dendrometer).

Precision agriculture follows the crop growth cycle in all its steps from seeding, planting, application of fertilizers and pesticides, through harvesting.

Customer profiling will be provided by social network analysis [1]. Farm production is based on digital agriculture [2]. Request for supply is sent to potential farmers according to the food on demand model [3]. Food transport quality model is based on tracing information, sensors, and open data by applying quality of transport - five-star model [4]. Quality of packaging (five star models) will be applied for RFID-based packaging [5]. Quality of Experience (QoE) metrics based on food provenance and traceability will provide subjective and objective measure of food quality perception [6].The combination of the Internet of Things with Blockchain Technology and Complexity Science creates entirely new opportunities to address our challenges in all areas [8]. 
Proc. of the Sixth International Conference on Advances in Computing, Electronics and Communication - ACEC 2017. Copyright (C) Institute of Research Engineers and Doctors. All rights reserved.

ISBN: 978-1-63248-138-2 doi: 10.15224/ 978-1-63248-138-2-03

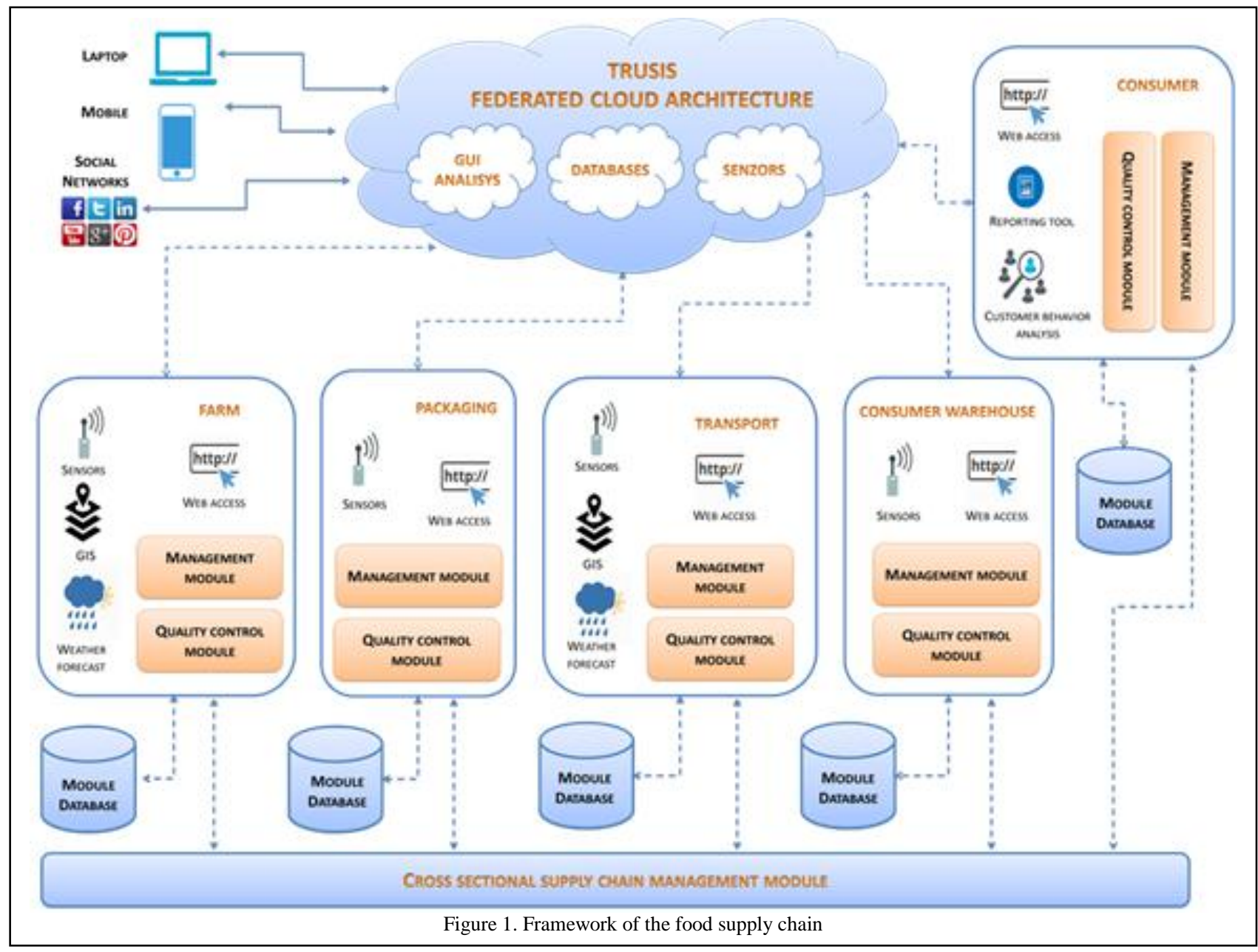

\section{MODELLING AND IMPLEMENTATION ISSUES}

The proposed research address a range of ICT-infrastructure related challenges such as cloud/edge/fog computing technologies as platform for TRUST in a modular way.

The actors of the supply chain are encouraged to introduce new business models on the module or supply chain level.

This project introduces new food on demand model and a high level of trust and quality control on the entire food supply chain. TRUST has modular architecture, so it will provide easy adaptation to change on the module level, independently from other part of the system. On the supply chain level, adaptation could be easy performed by adaptation or by adding new applications in the federated cloud. The main objectives of TRUST have been designed, agreed and will be developed by partners in this research whose core mission is to foster innovation in the Agri-food sector. For example, the partner POLO AGRIFOOD (member of the national cluster, http://www.clusteragrifood.it/en/) involves more than 400 SME, 40 big companies, and 20 Academies and Research Labs. It will act as the cooperative operational platform for the practical test and deployment of the research results through a unique range of stakeholders. The cluster of Agri-food companies and labs located across all EU (ranging from Spain passing through Italy, Austria, Slovenia, to reach Macedonia, Romania, and Greece) will have the unique opportunity by collaborating at this research to be at the forefront of the supply-chain technological innovation and development, to project the regions toward a number of emerging markets in the eastern regions of Europe. The excellence and international reputation of the food small and big industries will gain unprecedented strength by the innovative ICT tools and platform developed in the framework of this study within and beyond the involved regions. 
The integrations of data in a single information system in a trusted and secure way provided by RFID, NFC and Blockchains technologies will enhance the transparency, information flow and management capacity allowing better interactions of farmers with other part of supply chain, especially the consumer. The high level of supervision and control will be achieved by providing transparent exchange of sensors' information from farms and within the whole supply chain, efficient traceability and high level of cooperation.

Special attention will be given to the consumer behavior model based on social networks data as well as the modelling of the Quality of Experience (QoE). The data from these model are very important feedback from consumer to the all other supply chain actors.

Although the circular economy usually is focused on recycling, this should not be the top priority in our case because it is considered as high value reducer. Reuse, redistribute, remanufacture have similar importance. The objective of a circular economy is to keep products at their highest utility and value at all times and to provide sustainable food supply chain. This is the reason why we provide feedback from consumer to producer (farms), transformer (firms), packaging, transport and distribution (from warehouses) modules. The idea is to support Modular Design (mix \& match modularity) as a design approach of the circular economy.

Modularity of the supply chain fits and allow excellent usage of the block-chain technology which could be considered as decentralized, distributed database where all transactions from all modules are recorded, replicated and available for all modules and consumers. This is the way how we keep our system trusted, sustainable and reliable.

\section{CASE STUdY}

On the grape farm near the City of Skopje (near to the river Vardar) we instaled a group of sensors as shown on Fig. 2. The global connection of the sensors with the Base Station and IoT services in the Cloud is shown on Fig. 3.

Sensor node is equipped with sensors for measuring air temperature, air humidity, leaf wetness and soil moisture. LoraWAN protocol uses CSS (Chip Spread Spectrum) modulation that gives us the ability for data transmission of up to $10 \mathrm{~km}$ in line of site while providing low power consumption [9].

The sensor node uses the ATMega328p microcontroller [9] as processing unit. The purpose of the microcontroller is the coordination of the sensor node i.e. to collect, transform and encode the data from the sensors, activate and connect the transmission module with the network base station and send to the Cloud for further predictive analysis by corresponding IoT Cloud applications and services as can be seen on the same Fig. 3.

To achieve low power consumption we designed the cyclic measurements collection by using the ATMega328p inner watchdog timer. It was setup to execute single operation on every 18 minutes for 5 seconds runtime.

On Fig. 4, we presented the workflow diagram of the sensing process.

The instalation was recently done, so the first pleriminary results from the applications are expected on the beginning of October 2017 when the grape will be ready.

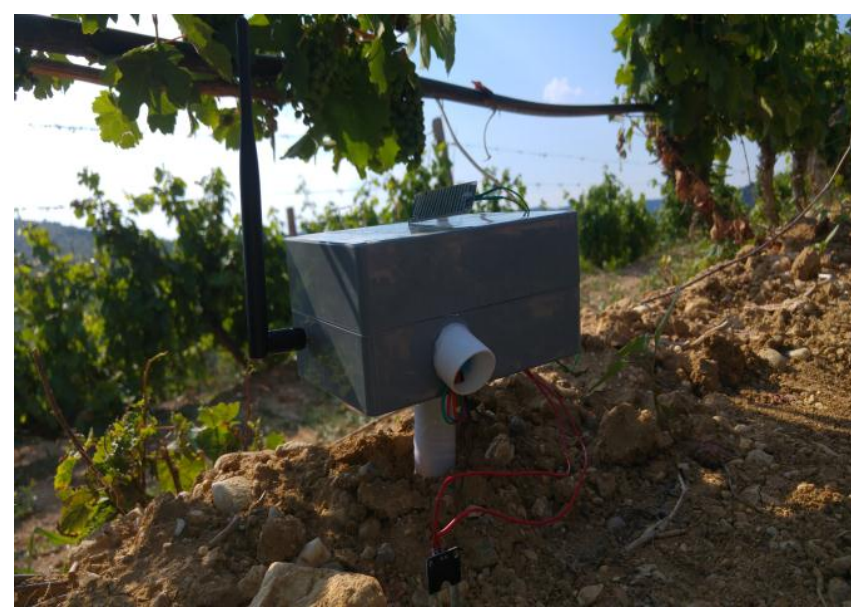

Figure 2. Sensors on the grape farm
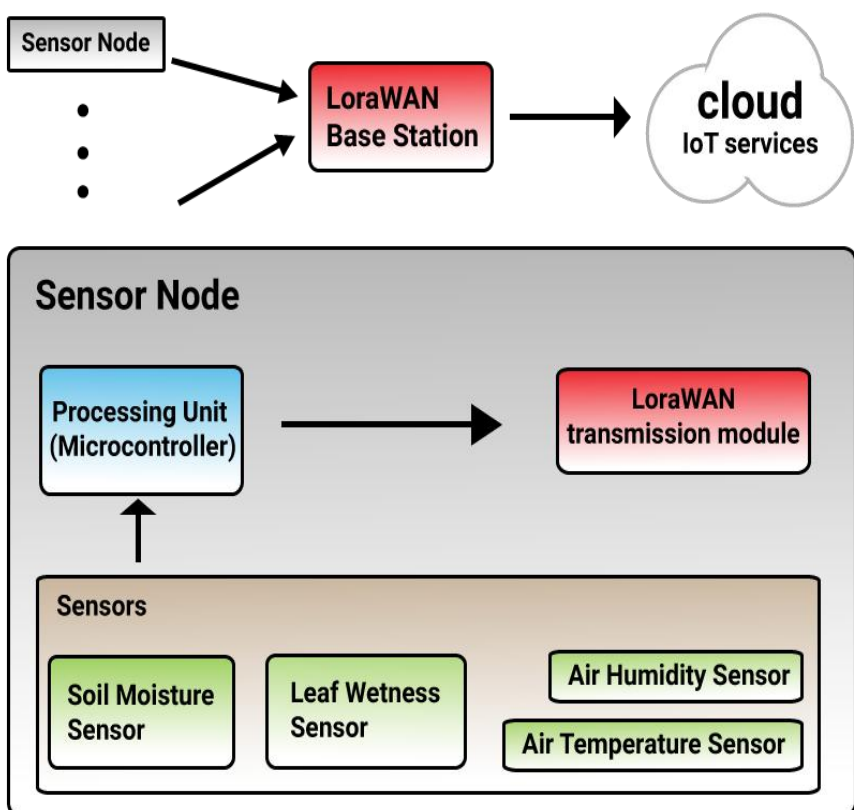

Figure 3. Connection to the Base station and Cloud (IoT service 
Proc. of the Sixth International Conference on Advances in Computing, Electronics and Communication - ACEC 2017. Copyright (C) Institute of Research Engineers and Doctors. All rights reserved.

ISBN: 978-1-63248-138-2 doi: 10.15224/ 978-1-63248-138-2-03

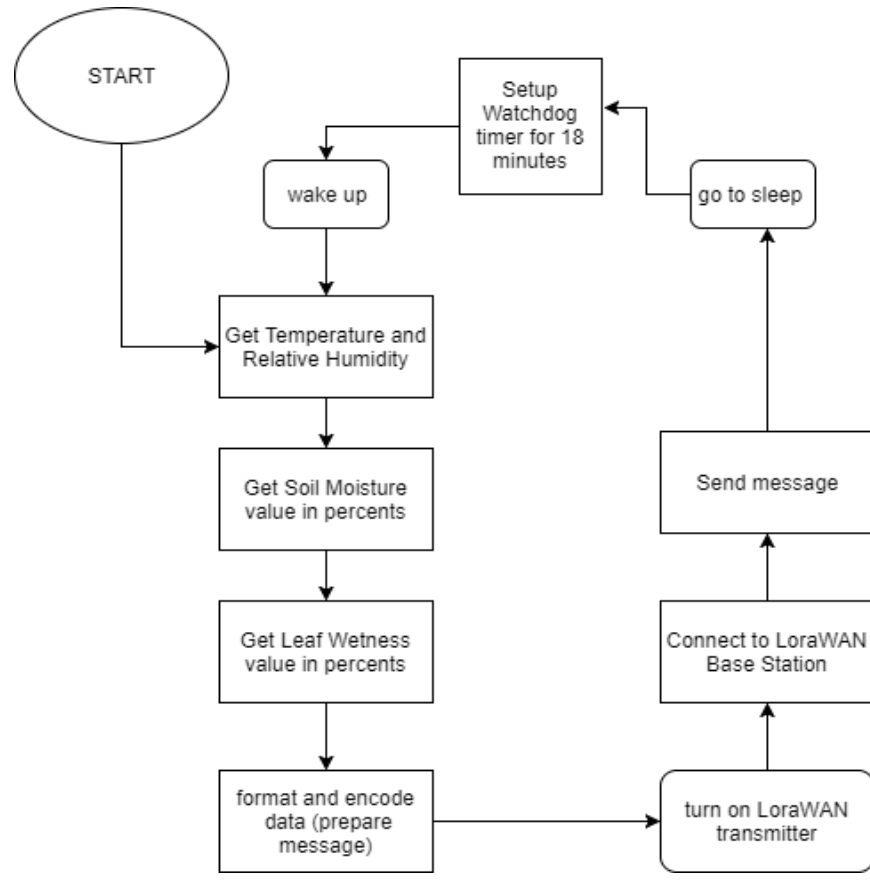

Figure 4. The workflow diagram of the sensing process

\section{v. TRUST STUDY}

We provided an trust qustionaire for fresh food products (FFP) for a group of 30 students from the University of Skopje. This study showed that the majority of students donot trust in the supply chain of FFP (see TABLE I). Hoever, the trust is correlated wiht the brand of the supply company (at least the brand is important for consumers).

\section{vi. ConClusion}

It is especially important to mention that the proposed study is generic. It means that it is applicable for any agriculture and food production. The grape was taken just as a case study to prove the possibility of cooperative trust food supply chain. It is worth to mention that the production of wine is a natural extension of this process.

In our future work, we plan to extend the benefits from the blockchain technology and in this way to provide transparent and secure supply chain system as well as trust in the origin and entire process of production, transport and distribution of the food on the market.

\section{REFERENCES}

[1] Xue, X., Computational Experiment-based Evaluation on Context-aware O2O Service Recommendation (http://ieeexplore.ieee.org/document/7779158/), IEEE Transaction on Service Computing, DOI: 10.1109/TSC.2016.2638083, 2016

[2] http://ec.europa.eu/programmes/horizon2020/en/news/digitising-agrifood-sector-workshop), Oct. 14, 2016, (last access June 20, 2017)

[3] Lien, T., On-demand business models have put some startups on life support, 2016, http://www.latimes.com/business/technology/la-fi-tn-endof-on-demand-snap-story.html, last acces June 20, 2017

[4] Reference Module in Food Science, Elsevier, 2016 http://www.sciencedirect.com/science/module/topic/9780081005965/Co ncept-000366?_si=1\&_ct=25, last access June 20, 2017

[5] Casillas, C., Food Packiging's Role in Food Safity, Food Processing Magazin, June, 2013

http://www.foodprocessing.com/articles/2013/food-packaging-foodsafety/, last access June 20, 2017

[6] Karadimce, A. \& Davcev, D. (2016). Perception of quality in cloud computing based services (pp. https://doi.org/10.1109/QoMEX.2016.7498925, IEEE QoMEX International Conference, Lisabon, 2016

[7] K. Schischke, M. Proske, N.F. Nissen, K.D. Lang, Modular Products Smartphone Design from a Circular Economy Perspective, Electronics Goes Green 2016+, Berlin, September 7 - 9, 2016

[8] K. Christidis, M. Devetskotiotis, Blockchain and smart contracts for the Internet of Things, IEEE Access, 2016

[9] LoRaWAN across the globe: LoRa Internet of Things networks overview, https://www.i-scoop.eu/internet-of-things-guide/iot-networklora-lorawan, (last access July 10, 2017)

TABLE I. TRUST TABLE

\begin{tabular}{|c|c|c|c|c|c|}
\hline Questions & $\begin{array}{l}1 \\
\text { (low) }\end{array}$ & 2 & 3 & 4 & $\begin{array}{l}5 \\
\text { (high) }\end{array}$ \\
\hline $\begin{array}{l}\text { Do you trust in the } \\
\text { declared origin of the fresh } \\
\text { food product (FFP)? }\end{array}$ & & $\mathrm{X}$ & & & \\
\hline $\begin{array}{l}\text { Do you trust in the FFP } \\
\text { quality related to } \\
\text { environmental problems? }\end{array}$ & & $\mathrm{X}$ & & & \\
\hline $\begin{array}{l}\text { How important is the } \\
\text { brand of the production } \\
\text { and packiging company? }\end{array}$ & & & & $\mathrm{X}$ & \\
\hline $\begin{array}{l}\text { Do you trust in transport } \\
\text { company of the FFP? }\end{array}$ & & $\mathrm{X}$ & & & \\
\hline $\begin{array}{l}\text { Do you trust the } \\
\text { distribution } \\
\text { werehousing } \\
\text { etc. }\end{array}$ & & $\mathrm{X}$ & & & \\
\hline $\begin{array}{l}\text { Do you trust the shelf life } \\
\text { deadline of the FFP }\end{array}$ & & $\mathrm{X}$ & & & \\
\hline $\begin{array}{l}\text { Do you trust on declared } \\
\text { chemical \& \& } \quad \text { other } \\
\text { characteristics for the FFP? }\end{array}$ & & & $\mathrm{X}$ & & \\
\hline $\begin{array}{l}\text { Do you trust in declared } \\
\text { conditions in the shop } \\
\text { where you bay the FFP } \\
\text { (temperature, humidity, } \\
\text { cleareness)? }\end{array}$ & & & $\mathrm{X}$ & & \\
\hline
\end{tabular}

